\title{
Partial discharge characteristics of enamel filled with micro and nano composite of $\mathrm{SiO}_{2}$ and $\mathrm{TiO}_{2}$
}

\author{
D. Edison Selvaraj \\ Asst Professor, Department of EEE, \\ Mepco Schlenk Engineering college, Sivakasi, India. \\ Email: edisonsivakasi@gmail.com
}

\begin{abstract}
Partial discharges were in general a consequence of local electrical stress concentrations in the insulation or on the surface of the insulation. A wide group of discharge phenomena such as internal discharges occurring in voids or cavities within solid or liquid dielectrics, surface discharges appearing at the boundary of different insulation materials, corona discharges occurring in gaseous dielectrics in the presence of inhomogeneous fields and continuous impact of discharges in solid dielectrics forming discharge channels were included as partial discharges. It has been observed that the use of nano composites in the matrix of polymeric materials can greatly improve the thermal, mechanical and electrical properties of polymeric nano composites. A nano composite $\left(\mathrm{TiO}_{2}+\mathrm{SiO}_{2}\right)$ has been tested as nano filler. The micro particles of $\mathrm{TiO}_{2}$ and $\mathrm{SiO}_{2}$ are converted into nano particles with the help of ball mill. Scanning electron microscope (SEM) has been used to augment the particle size of nano composite. These nano composites were mixed with standard (Elmo Luft 1A-FD) enamel with help of ultrasonic vibrator. The partial discharge characteristics of enamel, micro composite $\left(3: 1,1: 3,1: 1\right.$ of $\mathrm{SiO}_{2}$ and $\left.\mathrm{TiO}_{2}\right)$ filled enamel and nano composite $\left(3: 1,1: 3,1: 1\right.$ of $\mathrm{SiO}_{2}$ and $\left.\mathrm{TiO}_{2}\right)$ filled enamel were detailed and analyzed. The partial discharge measurement was carried out in uniform field electrode configurations. The mixing of nano composites of $\mathrm{SiO}_{2}$ and $\mathrm{TiO}_{2}$ taken in the proportion of $1: 3$ with enamel has a significant improvement in the values of partial discharge inception and extinction voltage by $25 \%$ and $35 \%$ respectively when compared to the partial discharge inception and extinction voltage of the enamel. Similarly, the enamel filled with micro composites of $\mathrm{SiO}_{2}$ and $\mathrm{TiO}_{2}$ taken in the proportion of $1: 3$ has an increase of $19 \%$ and $35 \%$ in the values of partial discharge inception and extinction voltage respectively when compared to the partial discharge inception and extinction voltage of the enamel.
\end{abstract}

Keywords: Partial discharge inception voltage, Partial discharge extinction voltage, Ball $\mathrm{Mill}_{1} \mathrm{SiO}_{2}, \mathrm{TiO}_{2}$, $\mathrm{Scanning}$ electron microscopy

\section{INTRODUCTION}

In the last few years, a great deal of attention has been given to the applications of nano dielectrics in the field of electrical insulating materials. It has been reported that the use of nano composites in the matrix of polymeric materials can greatly improve the thermal, mechanical and electrical properties of polymeric nano composites [1].

In the last few years, a great deal of attention has been given to the application of nano dielectrics in the field of electrical materials [2]. Nano dielectrics were a class of materials containing at least one phase at the nanometer scale. It has been reported that the use of nano fillers improves the corona resistance of polyimide films [4]. In addition, the use of nano composites of Silicon Di-Oxide $\left(\mathrm{SiO}_{2}\right)$ and Titanium oxide $\left(\mathrm{TiO}_{2}\right)$ in low density polyethylene has shown a smaller decrease in the resistivity of the polymeric matrix compared to micro fillers.

A driving force of the nano revolution was a continuous progress in the nano dielectrics towards increasing the level of stability, the reduction in the size and weight of the insulating materials [3]. In this paper, the partial discharge characteristics of enamel, micro composite $\left(3: 1,1: 3,1: 1\right.$ of $\mathrm{SiO}_{2}$ and $\left.\mathrm{TiO}_{2}\right)$ filled enamel and nano composite $\left(3: 1,1: 3,1: 1\right.$ of $\mathrm{SiO}_{2}$ and $\left.\mathrm{TiO}_{2}\right)$ filled enamel were analyzed and detailed.

\section{SYNTHESISATION CHARACTERIZATION NANO PARTICLES 2.1 Ball mill method}

There were several methods for creating nano particles, including both attrition and pyrolysis. In attrition, macro or micro scale particles were ground in a ball mill, a planetary ball mill, or other size reducing mechanism.

Ball mill was an efficient tool for converting micro powder into nano powder [1]. There are two ways of grinding: dry process and the wet process. The Silicon dioxide and titanium oxide nano filler was synthesized by this method. The pulverization planetary ball mill was universally applicable for quick dry or wet grinding of inorganic and organic samples. The sample material was crushed and disintegrated in a grinding bowl by grinding balls. The grinding balls and the micro powder in the grinding bowl were acted upon by the centrifugal forces due to the rotation of the grinding bowl about its own axis and due to the rotating supporting disc.

\subsection{Characterization of $\mathrm{SiO}_{2}$ and $\mathrm{TiO}_{2}$}


Nanoparticle characterization was necessary to establish understanding and control of nanoparticle synthesis and applications. Characterization was done by using a variety of different techniques such as transverse and scanning electron microscopy (TEM and SEM), atomic force microscopy (AFM), dynamic light scattering (DLS), X-ray photoelectron spectroscopy (XPS), X-ray diffraction (XRD), Fourier transform infrared spectroscopy (FTIR), ultraviolet-visible spectroscopy and nuclear magnetic resonance (NMR). Hitachi SU1510 was a compact, high performance scanning electron microscope. It was used for analyzing the particle size of $\mathrm{SiO}_{2}$ and $\mathrm{TiO}_{2}$ micro and nano particles. High resolution imaging was provided by this electron microscope.

\subsection{Curing}

The process of converting liquid state enamel into solid state sample is called as curing. The curing method used for enamel was radical initiator curing. In this process DDM (Diamino Diphenyl Methane) was used as curing agent [1]. $80 \%$ of enamel and $20 \%$ of epoxy resin was taken. DDM was taken in proportion to epoxy resin. For $1 \mathrm{~g}$ of resin 0.27 $\mathrm{g}$ of DDM was added. DDM was melted for 10 minutes for $60-80^{\circ} \mathrm{C}$. The enamel, resin and melted DDM were mixed in a beaker. The mixture was poured in the die which is coated by a Teflon sheet. Then the die was heated at $120^{\circ} \mathrm{C}$ for 2 hours and $130^{\circ} \mathrm{C}$ for 3 hours in an oven. The die was cooled and the solid sample was taken away from the oven.

\section{EXPERIMENTAL RESULTS}

\subsection{SEM Image Results}

The $\mathrm{SiO}_{2}$ and $\mathrm{TiO}_{2}$ particles were subjected to scanning electron microscopy to analyze the particle size and structure of the nano particles. The figures 1 to 4 show the SEM analysis of micro range of $\mathrm{SiO}_{2}$ and $\mathrm{TiO}_{2}$ before ball mill synthesization method.

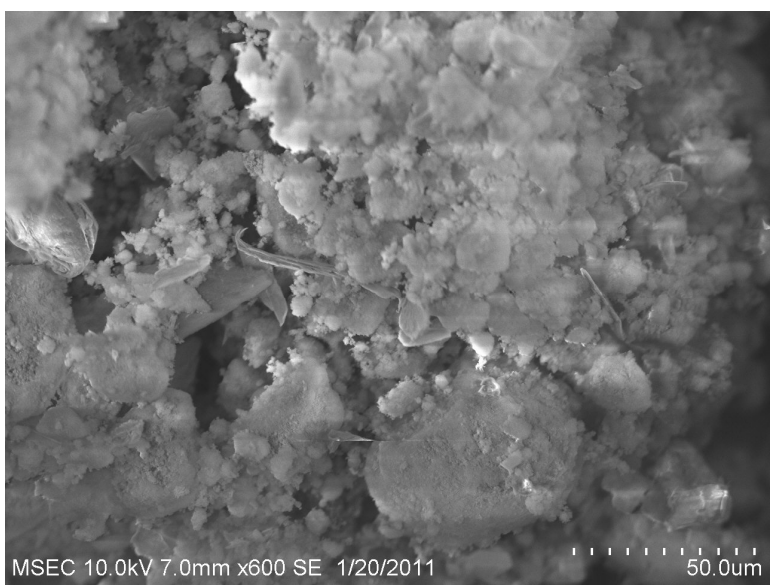

Figure $1 \mathrm{SEM}$ analysis of $\mathrm{SiO}_{2}$ at $50 \mu \mathrm{m}$

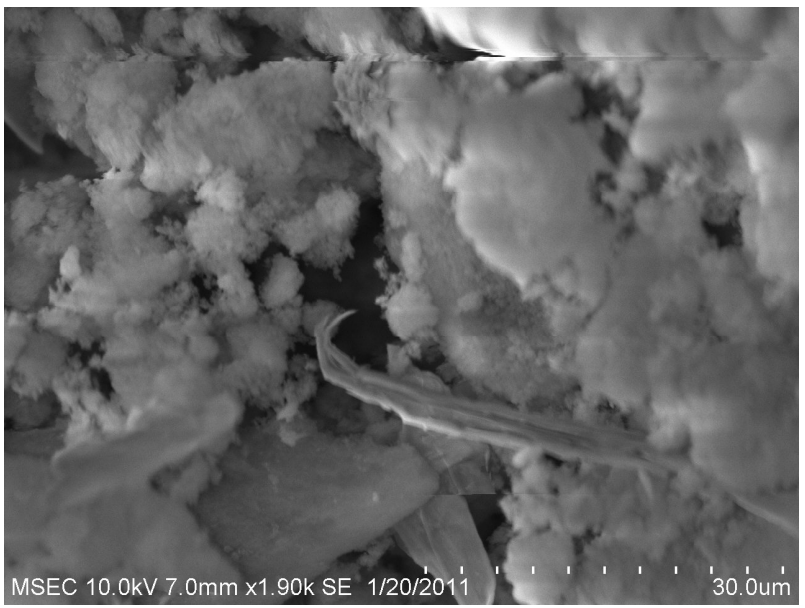

Figure $2 \mathrm{SEM}$ analysis of $\mathrm{SiO}_{2}$ at $30 \mu \mathrm{m}$

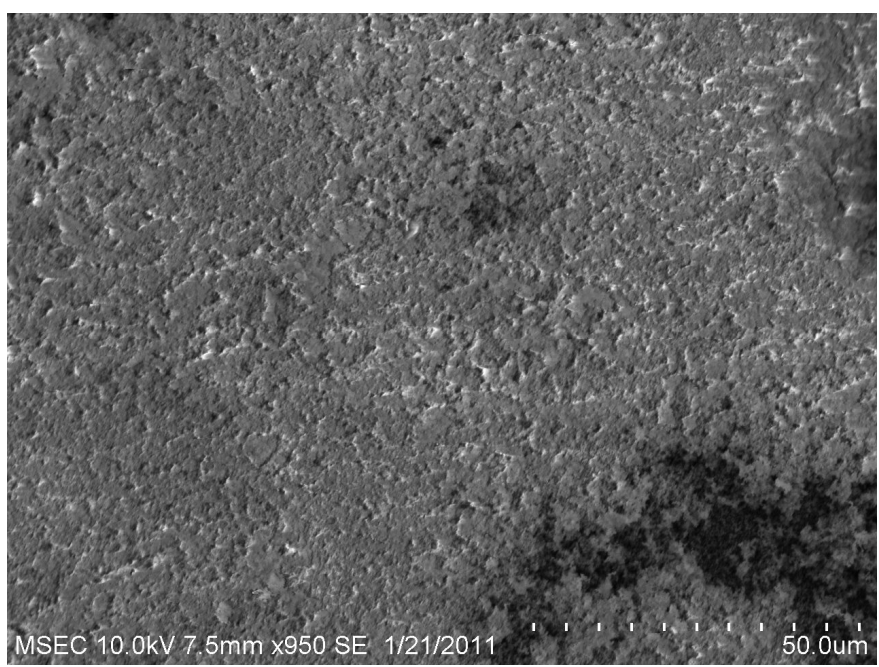


Figure 3 SEM analysis of $\mathrm{TiO}_{2}$ at $50 \mu \mathrm{m}$

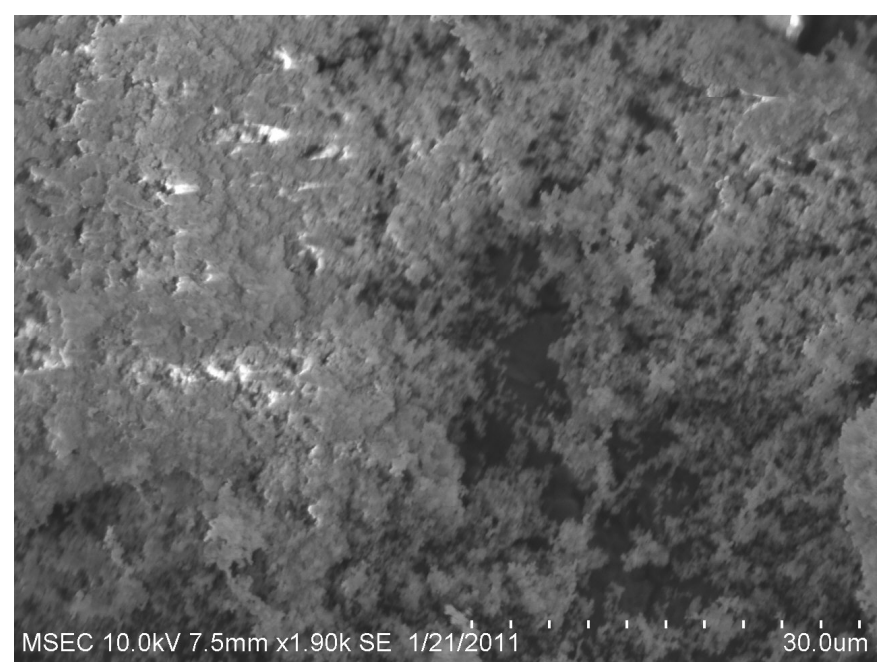

Figure $4 \mathrm{SEM}$ analysis of $\mathrm{TiO}_{2}$ at $30 \mu \mathrm{m}$

The figures 5 to 8 show the $\mathrm{SEM}$ analysis of $\mathrm{SiO}_{2}$ and $\mathrm{TiO}_{2}$ after ball mill synthesization method.

The micro size particle are converted into nano size with the help of Ball Mill .The SEM results show that the particles were in the form of nano metric range varies. The sizes of the particles were in the range from 40 to $100 \mathrm{~nm}$ size.

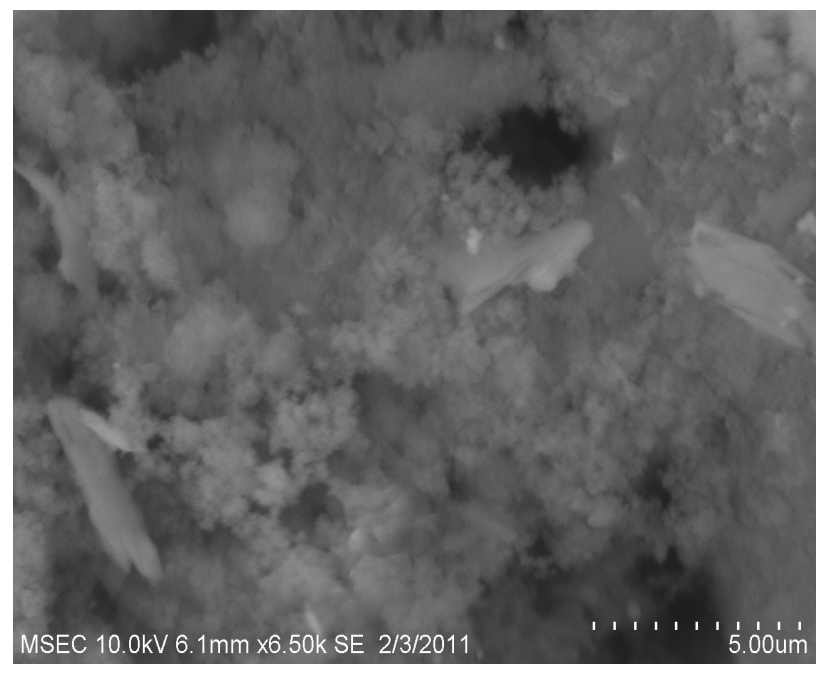

Figure $5 \mathrm{SEM}$ analysis of $\mathrm{SiO}_{2}$ at $5 \mu \mathrm{m}$

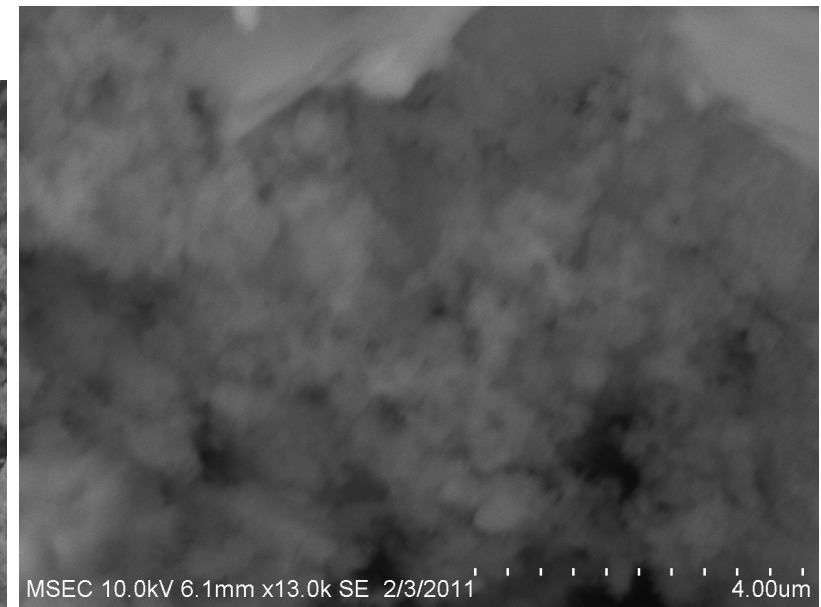

Figure $6 \mathrm{SEM}$ analysis of $\mathrm{SiO}_{2}$ at $4 \mu \mathrm{m}$

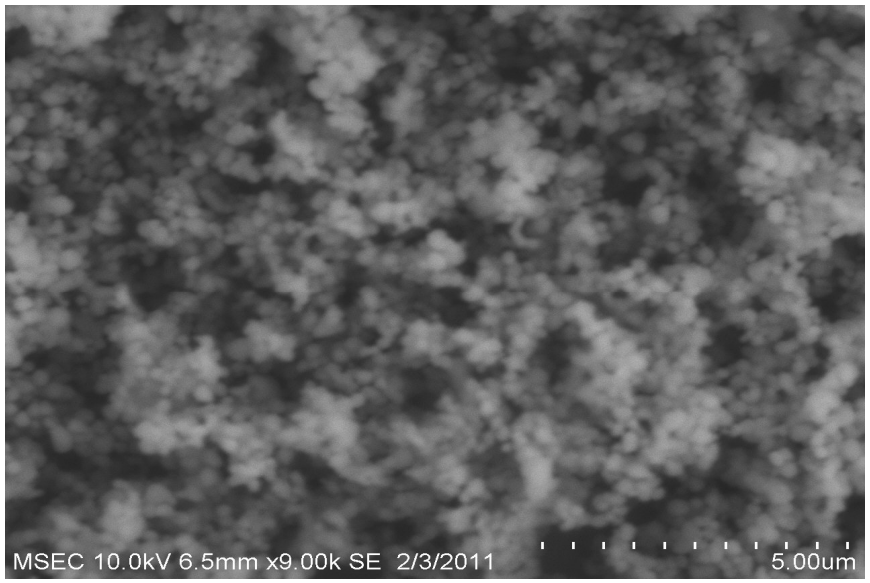

Figure 7 SEM analysis of $\mathrm{TiO}_{2}$ at $5 \mu \mathrm{m}$

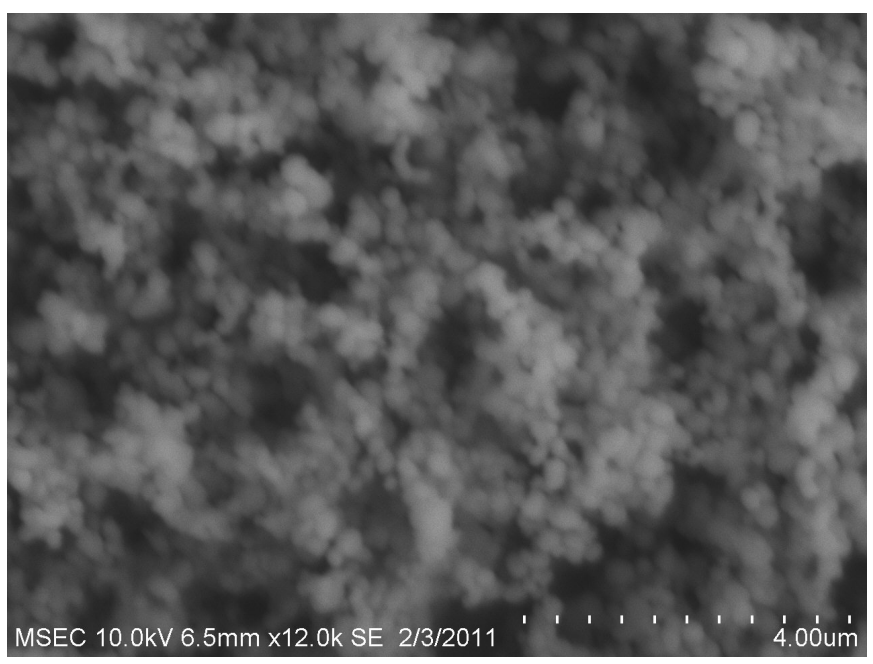

Figure 8 SEM analysis of $\mathrm{TiO}_{2}$ at $4 \mu \mathrm{m}$ 


\subsection{Partial Discharge Measurement}

\subsubsection{Partial discharge}

Partial discharges are in general a consequence of local electrical stress concentrations in the insulation or on the surface of the insulation. Generally such discharges appear as pulses of duration of much less than 1s. The partial discharge includes a wide group of discharge phenomena such as internal discharges occurring in voids or cavities within solid or liquid dielectrics, surface discharges appearing at the boundary of different insulation materials, corona discharges occurring in gaseous dielectrics in the presence of inhomogeneous fields and continuous impact of discharges in solid dielectrics forming discharge channels(treeing).

Every discharge event causes a deterioration of the material by the energy impact of high energy electrons or accelerated ions, causing chemical transformations of many types. The number of discharge events during a closed interval of time is strongly dependent on the kind of voltage applied and will be largest for AC voltages. The actual deterioration is dependent upon the material used. It is still the aim of many investigations to relate partial discharges to the life time of specified materials. The detection and measurement of discharges is based on the exchange of energy taking place during the discharge. These exchanges are manifested as electrical pulse currents, dielectric losses, EMR, sound, increased gas pressure and chemical reactions.

\subsubsection{Experimental set up for partial discharge measurement}

Partial discharge (PD) current pulses are very sharp pulses having a width of the order of nanoseconds. The IEC 60270 PD detectors are approximated the measured PD pulses as an impulse (less than $500 \mathrm{kHz}$ bandwidth).

\section{Auto Transformer:}

Auto transformer takes an input of $220 \mathrm{~V}, 50 \mathrm{~Hz}$, single phase and gives an output varies from 0 to $220 \mathrm{~V}$, $50 \mathrm{~Hz}$, single phase.

\section{H.V Transformer:}

The rating of high voltage transformer is $220 / 100 \mathrm{kV}, 50 \mathrm{~Hz}$, single phase. By varying the input from 0 to $220 \mathrm{~V}$ the output varies from 0 to $1000 \mathrm{kV}$ in proportion. Core made of iron type.

\section{Coupling capacitor:}

The coupling capacitor shall be mounted insulated or other measures shall be taken to ensure that ground foil can be connected to the insulated terminal of the measuring impedance AKV-D. Discharge free coupling capacitor is used in this setup. The coupling capacitor should preferably be high. $\mathrm{C}_{\mathrm{c}}=1000 \mathrm{pF}$.

\section{Measuring Impedance:}

$\mathrm{AKV}-\mathrm{D}$ is the measuring impedance, an inductor in parallel with a capacitor. The measuring impedance unit $\left(Z_{\mathrm{m}}\right)$ is located physically close to the high voltage coupling circuit and serves two main purposes:
It attenuates the test voltage present on the high voltage coupling circuit to the safe value for the measurement of the partial discharge signals. It matches the amplifier to the high voltage coupling circuit in insuring a flat frequency response across the full measurement band width. The measuring impedance unit $\left(\mathrm{Z}_{\mathrm{m}}\right)$ should be configured in such a way as to permit test voltage level monitoring and to observe the phase relationship between the test voltage and the partial discharge pulses; this technique helps to identify the nature of the discharges.

\section{Digital Storage Oscilloscope:}

Agilent oscilloscope 54621A is used for the display of the waveforms. The DSO is connected to the DTM at the backend. The oscilloscope displays the phase position of the partial discharge pulses with respect to the $\mathrm{AC}$ test voltage. The phase position of the partial discharge pulses with respect to the $\mathrm{AC}$ test voltage allows conclusions about the location of the partial discharges in the test object.

The arrangement of electrodes and experimental set up used for partial discharge measurements is shown in the figures 8,9 and 10 .

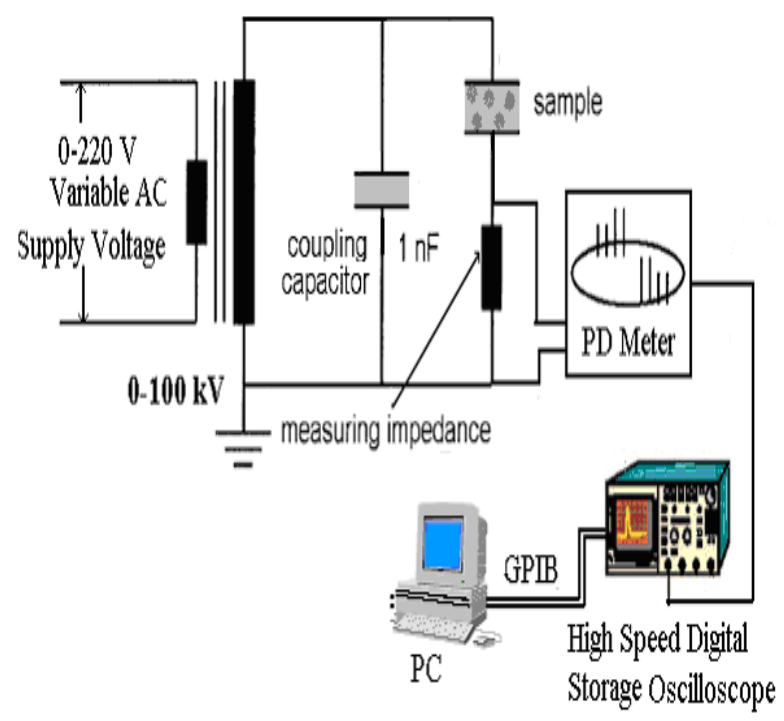

Figure 8 Circuit arrangements for Partial Discharge Measurement 


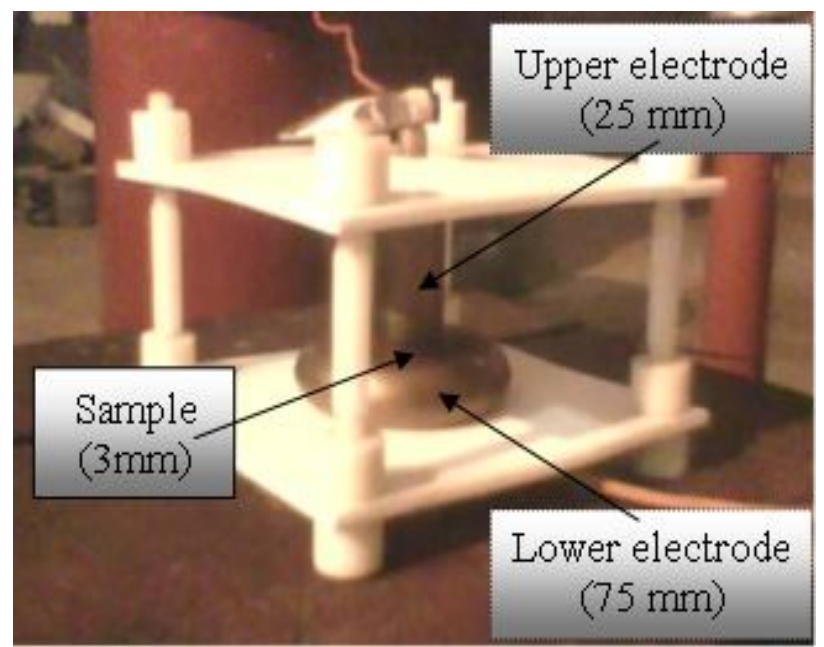

Figure 9 Electrode configuration for PD measurements

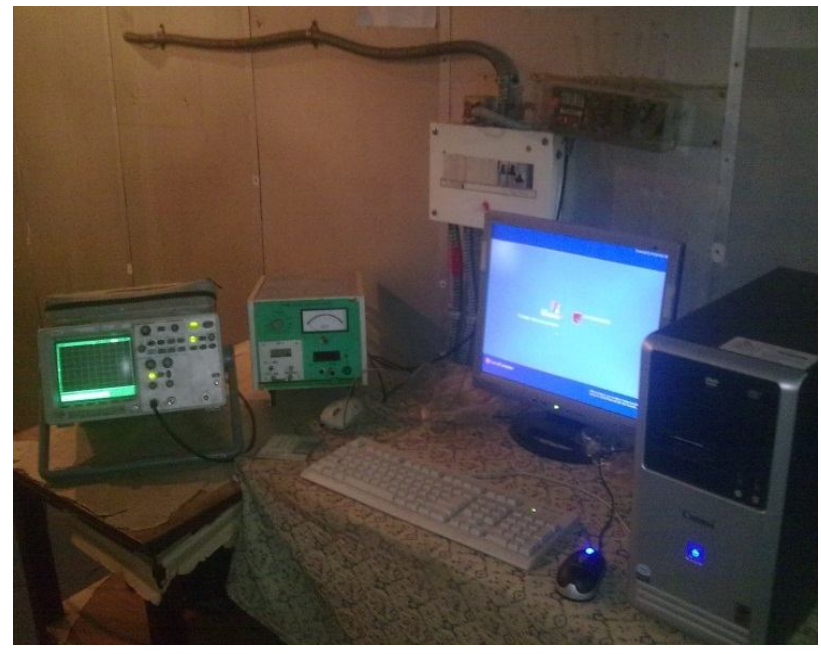

Figure 10 Experimental set up for partial discharge measurement for the sample

Plane-plane electrode configuration:

Sample thickness : $3 \mathrm{~mm}$

Diameter of upper electrode : $25 \mathrm{~mm}$

Diameter of lower electrode : $75 \mathrm{~mm}$

The entire arrangement in an insulating liquid with an appropriate dielectric constant (Ex: Insulating oil).

Allowed pC level:

The allowable $\mathrm{pC}$ levels for different conditions are shown in the table 1.

Table 1 Allowable pC level for different conditions

\begin{tabular}{|l|c|}
\hline Type of condition & Allowable level \\
\hline Shielded & Less than $2 \mathrm{pC}$ \\
\hline Unshielded & $7 \mathrm{pC}$ \\
\hline
\end{tabular}

\subsubsection{Experimental Procedure}

Before starting the experiment on the test specimen PD meter should be calibrated. The calibrator comprises a pulse generator in series with small capacitor of known value. The generator and the capacitor may be placed in the small box or may be connected together via a properly terminated coaxial cable of sufficient length to permit a calibration from the control room. The pulse generator should either have a known calibrated output level or its output level should be monitored. A suitable output level adjustment in the form of a calibrated potentiometer or a calibrated step attenuator should be provided.

The following three methods specify the test procedure for PD measurements, the first verifies the that test object is free from significant partial discharges up to a specified test voltages; second is used to determine the discharge inception and extinction voltages; and the third is used for measurement of discharge level at a voltage or voltages in range between the inception voltage and the maximum dielectric voltage.

A voltage, well below the specified discharge free voltage, is applied to the test object, gradually increased to the specified voltage, and maintained for the specified time; there after it is decreased and switched off. The object is consider to have the passed the test if the discharges do not exceeded a specified level.

A voltage well below the inception value is applied to the test object and gradually increased until discharge exceeds a specified level. The test voltage at this discharge limit is recorded. The voltage is then increased by $10 \%$ and there after reduced to a value at which the discharge ceases or become less than a specified level. The voltage corresponding to this limit is recorded. For some insulation systems, the extinction and inception values may be influenced by the length of the time that the test voltage is maintained above the inception level.

\subsubsection{Calibration}

The PDG pulse generator is connected in parallel with the test object and normally operated on position "50pC". The effective PD of the PDG simulates a known partial discharge intensity of the object. With the measuring range selector ' $\mathrm{E}$ ' of the DTM set on the respective position, the display is also set to $50 \mathrm{pC}$ with the potentiometer ' $G$ ' "CORR". For a defined test arrangement and with identical test objects, the correction factor has to be determined only once and holds good for all the measurements in the setup.

\subsubsection{Partial discharge inception and extinction voltage}

The partial discharge inception voltage and partial discharge extinction voltage for Plane-Plane electrode configurations were summarized in the following tables 2 .

Table 2 The partial discharge inception voltage and partial discharge extinction voltage for Plane-Plane electrode configurations

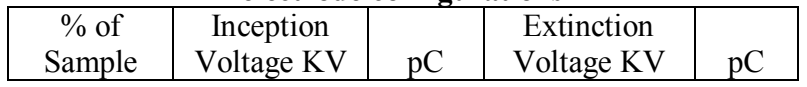




\begin{tabular}{|c|c|c|c|c|}
\hline $\begin{array}{c}\text { Pure } \\
\text { Enamel }\end{array}$ & 4.34 & 52 & 3.1 & 1.2 \\
\hline $1: 3$ micro & 5.15 & 42 & 4.2 & 1.1 \\
\hline $3: 1$ micro & 5.02 & 40 & 4 & 1 \\
\hline $1: 1$ micro & 4.91 & 44 & 3.8 & 1.3 \\
\hline $1: 3$ nano & 5.42 & 39 & 4.2 & 1.2 \\
\hline 3:1 nano & 5.32 & 50 & 4.1 & 1.1 \\
\hline 1:1 nano & 5.12 & 49 & 3.9 & 1.1 \\
\hline
\end{tabular}

\section{2 .6} of PD inception voltage

The measured pulse response

The measured pulse responses for PD inception voltage of various samples were shown in figures 9 to 15 .

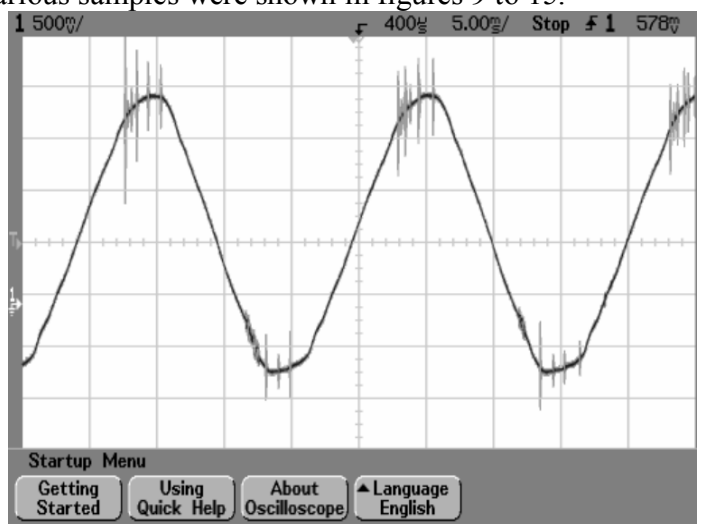

Figure 9 Measured pulse response for PD inception voltage of pure enamel

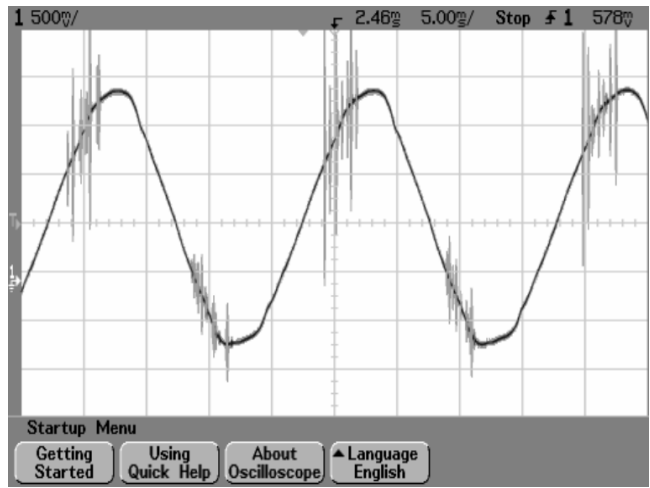

Figure 10 Measured pulse response for PD inception voltage of micro Composites $\left(\mathrm{SiO}_{2}+\mathrm{TiO}_{2}-1: 3\right)$

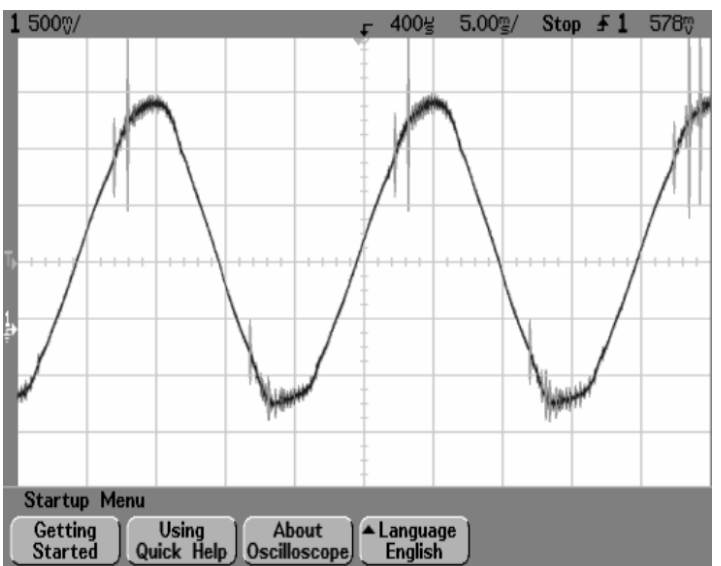

Figure 11 Measured pulse response for PD inception voltage of micro Composites $\left(\mathrm{SiO}_{2}+\mathrm{TiO}_{2}-3: 1\right)$

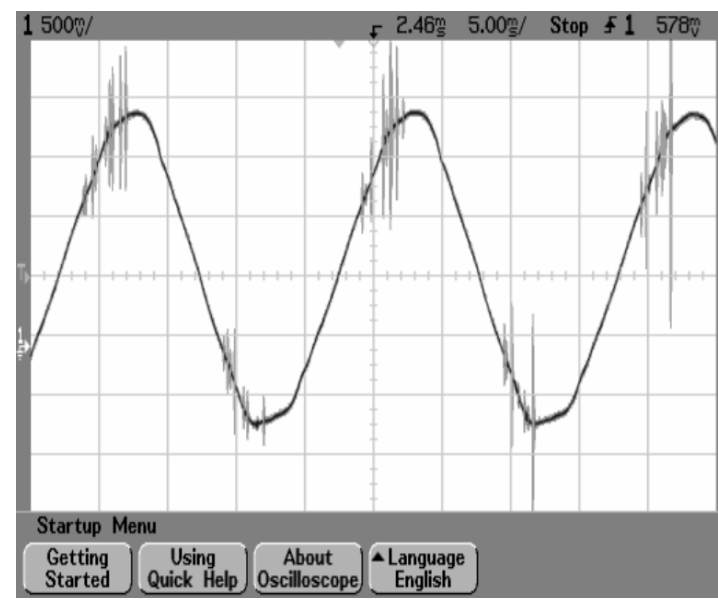

Figure 11 Measured pulse response for $\mathrm{PD}$ inception voltage of micro Composites $\left(\mathrm{SiO}_{2}+\mathrm{TiO}_{2}-1: 1\right)$

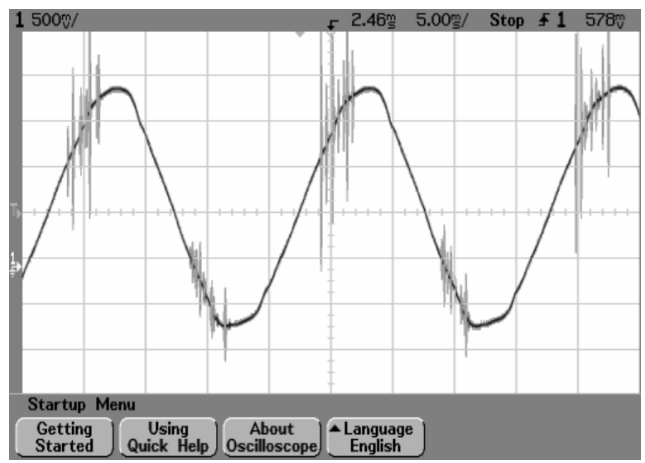

Figure 12 Measured pulse response for PD inception voltage of nano Composites $\left(\mathrm{SiO}_{2}+\mathrm{TiO}_{2}-1: 3\right)$ 


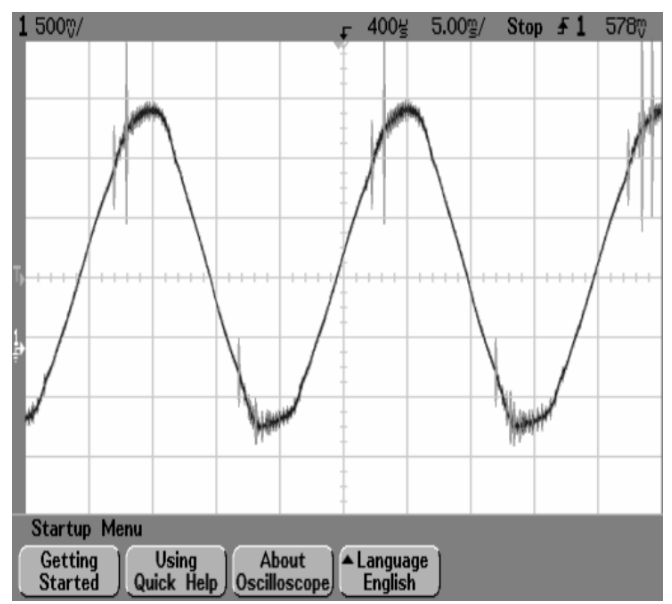

Figure 13 Measured pulse response for PD inception voltage of nano Composites $\left(\mathrm{SiO}_{2}+\mathrm{TiO}_{2}-3: 1\right)$

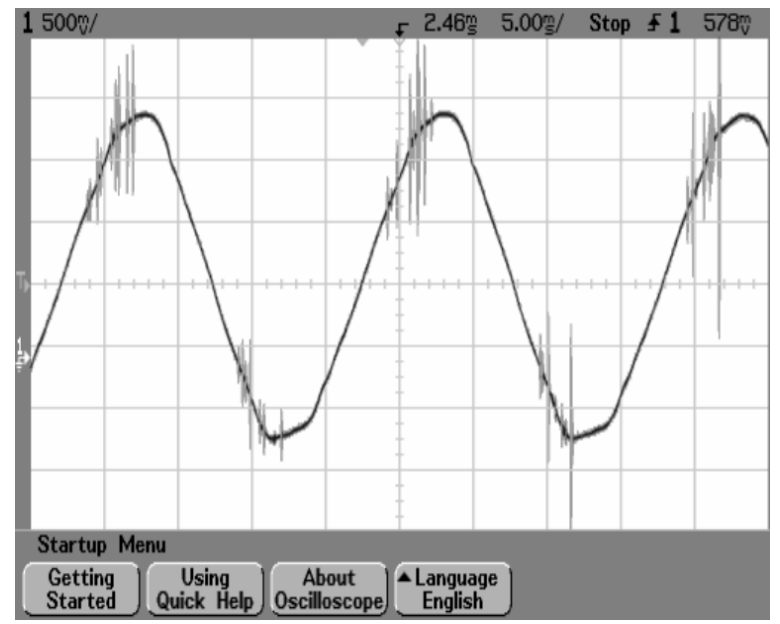

Figure 14 Measured pulse response for PD inception voltage of nano Composites $\left(\mathrm{SiO}_{2}+\mathrm{TiO}_{2}-1: 1\right)$

\section{CONCLUSION}

The addition of nano composites of $\mathrm{SiO}_{2}$ and $\mathrm{TiO}_{2}$ taken in the proportion of $1: 3$ as filler with enamel has a significant improvement in the values of partial discharge inception and extinction voltage by $25 \%$ and $35 \%$ respectively when compared to the partial discharge inception and extinction voltage of the enamel. Similarly, the enamel filled with micro composites of $\mathrm{SiO}_{2}$ and $\mathrm{TiO}_{2}$ taken in the proportion of 1:3 has an increase of $19 \%$ and $35 \%$ in the values of partial discharge inception and extinction voltage respectively when compared to the partial discharge inception and extinction voltage of the enamel.

\section{ACKNOWLEDGEMENT}

The author expresses his sincere gratitude to the almighty God and the Lord Jesus Christ for His blessings for His research. The authors also express their sincere thanks to the Department of Mechanical Engineering and Physics, Mepco Schlenk Engineering College, Sivakasi, India and the Division of High Voltage Engineering, College of Engineering, Guindy, Anna University, Chennai, India for the sample preparation and testing of samples.

\section{REFERENCES}

[1] C. Pugazhendhi Sugumaran, M.R.Mohan and K.Udayakumar, "Investigation of Dielectric and Thermal Properties of Nano-filler (ZrO2) Mixed Enamel", IEEE Transaction on Dielectrics and Electrical Insulation: Vol.17, No.6, 2010.

[2] Hulya Kirkici, Mert Serkan, K.Koppisetty, "Nanodielectric Materials in Electrical Insulation Application", IEEE, 2005.

[3] Takahiro Imai, Gen Komiya, Kiyoko Murayama, Tamon Ozaki, "Improving Epoxy-based Insulating Materials with Nano-fillers toward Practical Application", IEEE 2008.

[4] Guoqin Zhang, Guangning Wu, Laisheng Tong, Enguang, "Study of Nano $\mathrm{TiO}_{2}$ Filler in the Corona resistant Magnetic Wire Insulation Performance of Inverter-fed Motor", Proceedings of international Symposium on Electrical Insulating Materials, June 59, 2005, Kitakyushu, Japan A3-8, 2005.

[5] Edison Selvaraj. D, Pugazhendhi Sugumaran. C and SivaPrakash. A, "Characterization of Electrical and Thermal Properties of Enamel Filled with Carbon Nanotubes", PEIE 2012, LNEE, pp. 496-502, 2012. 